\title{
Ultrasonic Welding of Thermoplastic Composites
}

\author{
Irene Fernandez Villegas* \\ Aerospace Structures and Materials Department, Faculty of Aerospace Engineering, Delft University of Technology, Delft, \\ Netherlands
}

Ultrasonic welding is a very fast and energy-efficient technique for the joining of thermoplastic composites. This article looks into main aspects of ultrasonic welding of continuous fiber-reinforced thermoplastic composites, namely energy directors, process parameters, in situ process monitoring, welding of dissimilar composite materials and upscaling routes. From the author's viewpoint these are key topics for deepening our insight into the ultrasonic welding process and, eventually, for enabling its future industrialization.

Keywords: polymer composites, joining, fusion bonding, in situ monitoring, energy director

\section{INTRODUCTION}

Thermoplastic composites are weldable, they feature cost-efficient manufacturing routes, they offer the possibility to be recycled and they are by nature more damage tolerant than traditional thermoset composites. Owing to these general advantages, certain industrial sectors such as aviation and automotive industries are experiencing a shift of focus from metals and thermoset composite toward thermoplastic composites (Favaloro, 2018; Gardiner, 2018; Ishikawa et al., 2018). This shift is in particular driven by weight reduction (from metals to composites), cost and production time reduction (from thermoset to thermoplastic composites) and recyclability (from thermoset to thermoplastic composites) requirements imposed by our current societal needs. One of the major factors contributing to reduced manufacturing cost and time in thermoplastic composites is their ability to be welded. Consequently, in the last decades there has been an increased effort in the development of welding techniques applicable to thermoplastic composites. Some of the most promising thermoplastic composite welding techniques are resistance, induction, laser, and ultrasonic welding (Ageorges et al., 2001). Among them, ultrasonic welding stands out as a very fast, and energy efficient process (Villegas et al., 2012).

Ultrasonic welding is cataloged as a friction welding technique in which the parts to be welded, i.e., adherends, are subjected to high frequency (typically between 20 and $50 \mathrm{kHz}$ ) and low amplitude (typically between 10 and $250 \mu \mathrm{m}$ ) mechanical vibrations as well as to a static welding force. The mechanical vibrations are generated by a piezoelectric converter and applied onto the adherends by means of a sonotrode, which is also responsible for exerting the welding force. A booster and the sonotrode itself are responsible for amplifying the vibrations. Depending on the orientation of the mechanical vibrations with regards to the welding interface, ultrasonic welding can be further subdivided into plastic ultrasonic welding, in which the vibrations are introduced transverse to the welding interface, and metal ultrasonic welding, in which the vibrations are introduced parallel to the welding interface (Balle et al., 2009). Ultrasonic welding of thermoplastic composites generally makes use of the plastic variant of the welding process. In plastic ultrasonic welding, simply referred to as ultrasonic welding hereafter, so-called energy directors, i.e., resin-rich features, are typically used to concentrate heat generation at the welding interface through a 
combination of surface friction and viscoelastic heating (Potente, 1984). According to the work of Zhang et al. (2010), surface friction is the primary heating mechanism from room temperature until the thermoplastic resin approaches its glass transition temperature. From there on surface friction gives way to viscoelastic heating, which is a significantly faster heating mechanism. The viscoelastic friction heating rate can be described through the following equation (Benatar and Gutowski, 1989):

$$
\dot{Q}_{v}=\frac{\omega \cdot \mathbf{E}^{\prime \prime} \cdot \varepsilon^{2}}{2}
$$

where $\omega$ is the frequency of the vibration, $E^{\prime \prime}$ is the loss modulus of the material and $\varepsilon$ is the cyclic strain imposed in the material, directly linked to the amplitude of the vibration. The ultrasonic welding process can be divided into three phases: (i) build up phase in which the sonotrode makes contact with and starts applying force onto the adherends until a certain trigger force is reached; (ii) vibration phase, in which mechanical vibrations of a certain amplitude are applied to the adherends causing heat to be generated; and (iii) consolidation phase in which the welded parts are allowed to cool down under a certain force. During the vibration phase, heat is generated preferentially in the energy director and then transferred to the adherends. In order to create a welded joint, intimate contact followed by molecular inter-diffusion at the welding interface (typically, the interface(s) between adherends and energy director) needs to be achieved. In order to achieve molecular inter-diffusion across the welding interface amorphous and semi-crystalline thermoplastic resins need to be brought above their glass transition and their melting temperature, respectively.

Ultrasonic welding of unreinforced thermoplastic resins is widely used in the plastics industry, e.g., packaging, medical, and electronics industries (Grewel et al., 2003). However, to the author's knowledge, ultrasonic welding of continuous fiberreinforced thermoplastic composites does not hold any current substantial industrial application. Reasons for this could be a so far modest industrial use of thermoplastic composites as well as the complexity of the welding technique itself (application of energy directors, understanding and prediction of heat generation and weld quality, upscaling, etc.). Despite these challenges, the very short processing times, ease of automation and excellent weld quality (Grewel et al., 2003; Villegas et al., 2012) make ultrasonic welding of thermoplastic composites a very interesting future structural and semi-structural joining process in industries with high production rates such as the automotive industry or industries that deliver very complex products with high part count numbers, such as the aircraft industry. This article looks into main aspects of ultrasonic welding of continuous fiber-reinforced thermoplastic composites (simply referred to as thermoplastic composites hereafter), i.e., energy directors, process parameters, and process control, in situ process monitoring, upscaling routes, and finally welding of dissimilar composite materials. From the author's viewpoint, these are key topics for deepening our insight into the ultrasonic welding process and, ultimately, for enabling its future industrialization.

\section{ENERGY DIRECTORS}

As mentioned in section Introduction, the role of the energy directors in the ultrasonic welding process is to concentrate heat generation. That is achieved by ensuring that (i) relative movement is possible between the energy directors and at least one of the adherends (promotion of surface friction) and (ii) the stiffness of the energy director is lower than that of the adherends [promotion of viscoelastic heating, which as shown in Equation (1) is directly proportional to the square of the cyclic strain undergone by the material].

In ultrasonic welding of unreinforced thermoplastic parts, energy directors are typically molded on the parts to be welded as resin protrusions of different size and geometry referred to as traditional energy directors hereafter. Typical traditional energy director shapes are triangular, rectangular, and semicircular. The shape of the energy director is believed to influence heat generation rates at the welding interface (Yan et al., 2007). In ultrasonic welding of thermoplastic composites traditional energy directors have also been successfully used (Benatar and Gutowski, 1989; Harras et al., 1996; Liu and Chang, 2001; Villegas and Palardy, 2017); however, they require one additional manufacturing step, i.e., molding of the energy directors on top of an already consolidated thermoplastic composite laminate. Alternatively, loose layers of neat thermoplastic resin, the socalled "flat energy directors" or "tie layers," are also successful in concentrating heat at the welding interface (Ramarathnam et al., 1992; Tateishi et al., 1992; Levy et al., 2014; Villegas et al., 2015) owing to the lower compressive stiffness of the neat resin, i.e., energy director, as compared to that of the composite laminates, i.e., adherends. Flat energy directors offer increased simplicity since they do not need to be molded on the adherends and hence can be placed at the welding interface prior to the welding process. It should however be noticed that the thickness of the flat energy director plays a major role on its ability to concentrate heat generation. Decreasing the thickness of the flat energy director causes the cyclic strains and hence heat generation rates in both the adherends and the energy director to increase. Consequently below a certain thickness threshold the energy director loses its ability to concentrate heat generation (i.e., the energy director and the adherends heat up and melt simultaneously) and the risk of overheating at the welding interface increases (Palardy and Villegas, 2017). Flat energy directors with thicknesses of $250 \mu \mathrm{m}$ or higher have been shown to adequately concentrate heat generation and to produce high quality welds for different thermoplastic composite materials (Villegas, 2014; Villegas et al., 2015). Flat energy directors with thicknesses below $100 \mu \mathrm{m}$ have been found to result in weld lines with voids, most likely caused by overheating of the thermoplastic resin (Palardy and Villegas, 2017; Jongbloed et al., 2018).

Differences and similitudes between traditional triangular and flat energy directors in ultrasonic welding of carbon fiber 
reinforced polyphenylene sulfide (CF/PPS) composite single-lap shear coupons were investigated in Villegas et al. (2015) and Villegas and Palardy (2017). The results showed no significant effect of the energy director type, i.e., flat vs. traditional, in the quality of the welded joints (fully welded area, similar lap shear strength), the vibration (heating) time or the energy consumed during the welding process (Figure 1). However, as expected, a major difference was found in the melting and flow behavior of the energy directors which in turn affected the vertical displacement of the sonotrode (or collapse of the joint) during the welding process. The triangular energy directors gradually melt and flow causing a steady downward displacement of the sonotrode from virtually the beginning of the vibration phase (Figure 2). Contrarily, the flat energy directors gradually melt but they do not flow until they are molten in their entirety. This means that the sonotrode does not experience any downward displacement during typically the biggest part of the vibration phase. These differences, which did not have any measurable impact on ultrasonic welding of coupons, are, however, of importance in applications where the vertical displacement of the sonotrode is constrained (Senders et al., 2016; Jongbloed et al., 2018).

Welding without energy directors, which would in principle offer the most straightforward procedure, has been explored recently in the context of generation of spot welds, i.e., welds with an area smaller than the total overlap (Gao et al., 2018; Li et al., 2018; Tutunjian et al., 2018). One of the main side effects of not using an energy director is that it is difficult to control the location at the interface where heating occurs (Li et al., 2018). This issue can be overcome by either using a blank holder, i.e., a hollow clamp around the sonotrode (Li et al., 2018), or by properly designing the ratio between the anvil/adherend and the sonotrode/adherend contact surfaces (Tutunjian et al., 2018). Another side effect of not using an energy director is the risk of overheating of the thermoplastic resin which typically results in porosity at the weld interface (Gao et al., 2018; Tutunjian et al., 2018). This effect might be susceptible of being counteracted by

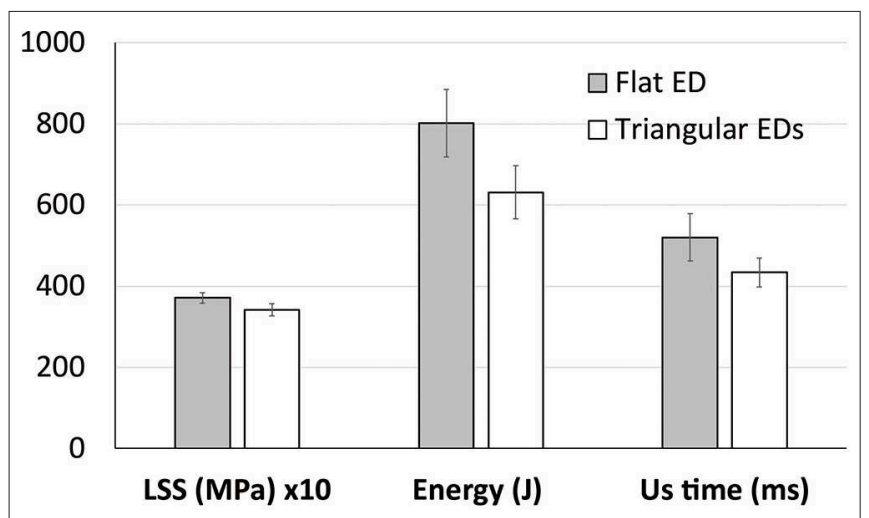

FIGURE 1 | Lap shear strength (LSS), welding energy and vibration (Us) time for CF/PPS single-lap coupons welded with flat and triangular energy directors (Villegas et al., 2015; Villegas and Palardy, 2017). proper process control, as explained in section in situ Monitoring of this paper.

\section{PROCESS PARAMETERS}

The parameters that govern the vibration phase in the ultrasonic welding process are the welding force, vibration amplitude and the vibration time. It should be noted that the frequency of the vibration has a fixed value for each specific ultrasonic welding machine, therefore it is typically not considered as a parameter of the vibration phase of the ultrasonic welding process.

The welding force and the vibration amplitude determine the rate at which heat is generated during the welding process. High values of welding force and/or vibration amplitude lead to fast heat generation, whereas low force and/or amplitude result in relatively slow heat generation (Tolunay et al., 1983; Villegas, 2014). As mentioned in section Introduction, heat generation in ultrasonic welding is a combination of surface and viscoelastic friction. Viscoelastic friction heating is related to the amplitude of vibration through Equation (1). Surface friction is, in turn, related to the normal stresses at each location of the welding interface(s), $N$, which can be divided into a static and a dynamic components, $N_{s}$ and $N_{d}$, respectively, according to the following equation:

$$
N=N_{s}+N_{d}=\frac{F_{w}}{S_{w}}+\sigma_{n}
$$

Where $F_{w}$ is the static welding force, $S_{w}$ is the area to be welded and $\sigma_{n}$ is the dynamic normal stress generated by the vibration applied during the welding process. A lower bound for the dynamic normal stress can be computed by considering a vertical uniform sinusoidal deformation equal to the amplitude

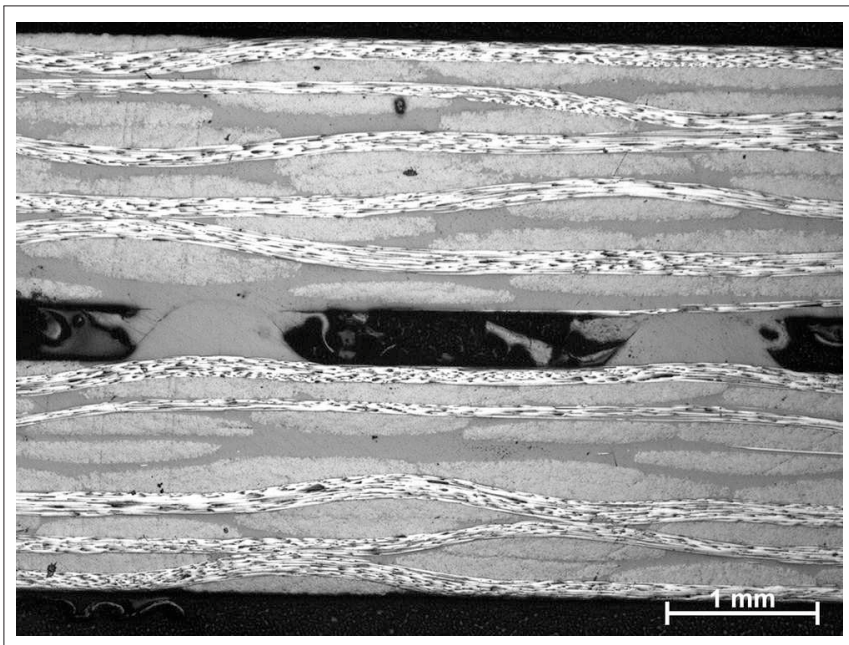

FIGURE 2 | Optical cross-section micrograph showing melting of the tip of the energy directors and resin squeeze out to the sides at the beginning of the welding process. Reprinted from Villegas and Palardy (2017) with permission from Taylor and Francis. 
of the vibration divided by the thickness of the welding stack (i.e., adherends plus energy director), leading to the following relationship (Levy et al., 2014):

$$
\sigma_{n}>\frac{A \cdot E_{w}^{\prime}}{\boldsymbol{t}_{w}}
$$

Where $A$ is the amplitude of vibration, $E_{w}^{\prime}$ is the elastic modulus of the welding stack and $t_{w}$ is the thickness of the welding stack. According to Levy et al. (2014) for typical force and amplitude values in ultrasonic welding of thermoplastic composites, the dynamic normal stresses are significantly higher than the static ones. In an ideal welding process in which the sonotrode were permanently in contact with the top composite adherend, the amplitude of vibration could hence be expected to play a bigger role in overall heat generation than the welding force. However, as clearly described by Nonhof and Luiten (1996) the contact between the sonotrode and the top composite adherend is at times lost during the vibration phase of the process resulting in the so-called hammering effect. By comparing the experimental and numerical values for the power dissipated during ultrasonic welding, Levy et al. (2014) estimated a hammering coefficient, i.e., ratio between the actual amplitude transmitted to the welding stack (i.e., adherends plus energy director) and the nominal amplitude (Palardy et al., 2018), as low as 13\% (ultrasonic welding of $2 \mathrm{~mm}$-thick CF/PEI composites with a $0.25 \mathrm{~mm}$ thick flat energy director and welding force and peak-to-peak amplitude of $500 \mathrm{~N}$ and 83 microns, respectively). This was later on confirmed by the work of Palardy et al. (2018) in which the amplitude transmitted to the top adherend was experimentally measured (Figure 3). The hammering effect is very sensitive to a number of factors including the compliance of the welding stack and the welding force. In particular, as the welding force decreases the hammering effect has been observed to significantly increase. This effect of the welding force on the actual vibration transmitted to the welding stack could explain why in an experimental study by Villegas (2014) the welding force, and not the amplitude of vibration, was found to be the biggest influential factor on the heating time during ultrasonic welding of carbon fiber reinforced polyetherimide (CF/PEI) composites with a flat PEI energy director and different combinations of welding parameters.

The third parameter, the vibration time, determines the duration of the vibration phase and hence the amount of energy invested in creating the welded joint (for a certain combination of welding force and amplitude) and ultimately its quality. In micro-processor controlled ultrasonic welders the duration of the vibration phase not only can be controlled directly, i.e., through setting a certain vibration time, but also indirectly. Typical parameters used to indirectly control the duration of the vibration phase are the welding energy and the vertical displacement of the sonotrode. Consequently the ultrasonic welding process can be "energy controlled" or "displacement controlled," i.e., the vibration is stopped when a prescribed energy value or a prescribed vertical displacement of the sonotrode is reached, respectively. It should be noted that the welding energy is calculated as the area under the curve of the power dissipated during the process and as such consists not only of the energy used to create the welded joint but also the energy dissipated into the surroundings of the welding overlap (e.g., adherends, clamping jig, base, etc.). The vertical displacement of the sonotrode refers to the collapsing of the initial distance between the two surfaces to be welded. Indirectly controlling the duration of the vibration phase through either the welding energy or the displacement of the sonotrode has been shown to provide welded

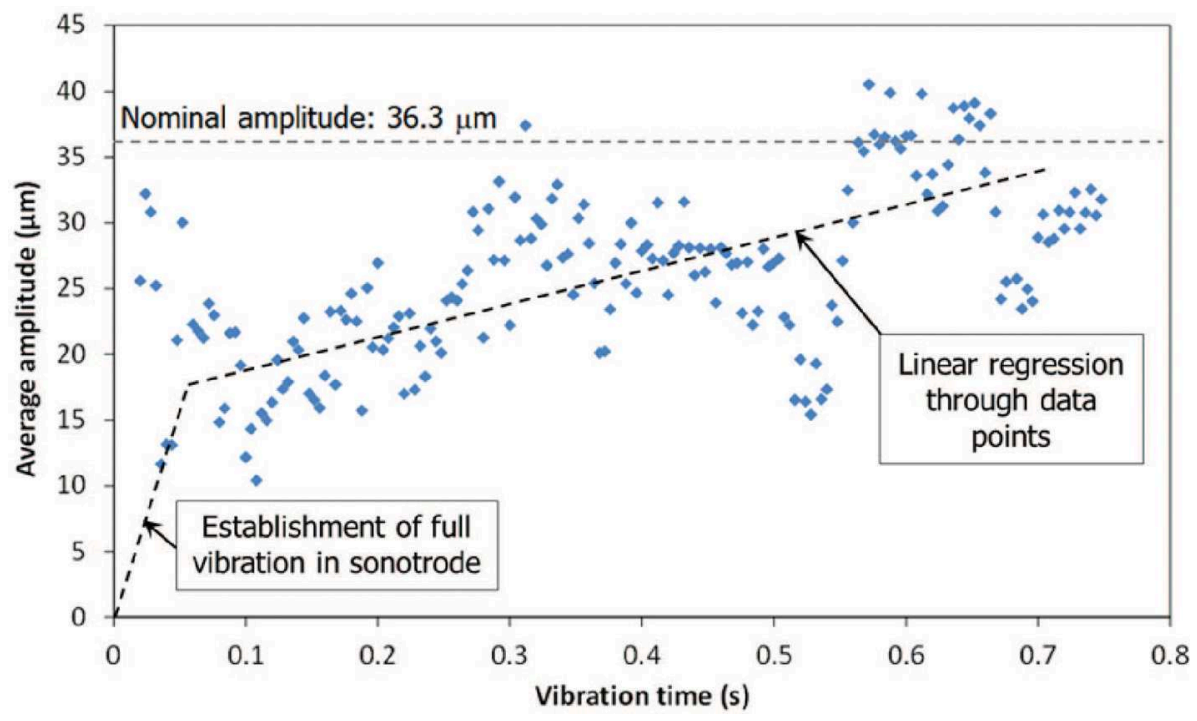

FIGURE 3 | Estimated amplitude of vibration transmitted to the top adherend during ultrasonic welding of CF/PEI single-lap coupons (welding force 1,500 N, peak-to-peak vibration amplitude $2 \times 36.3 \mu \mathrm{m}$ ) as measured with laser sensor $2 \mathrm{~mm}$ away from the sonotrode. Note that the amplitude values represented in the graph are half of the peak-to-peak amplitude values. Reprinted from Palardy et al. (2018) with permission from Elsevier. 
joints with a more consistent quality than direct time control (Harras et al., 1996; Villegas, 2014). However, the welding energy is highly sensitive to a number of factors in the welding process such as the thickness of the adherends (Villegas, 2014) or the way in which they are clamped (Zhao et al., 2018). Consequently, changes in the welding configuration might require an update of the welding energy needed to achieve a certain weld quality. This is illustrated by the results of experimental research carried out by Zhao et al. (2018) on multi-spot welded joints obtained through a sequential ultrasonic welding process. A specific characteristic of the sequential ultrasonic welding process is that the stiffness of the multi-spot welded joint varies with each new welded spot. Such stiffness variation was found to require an update of the welding energy (energy-controlled process) for each new spot in order to obtain spots with consistent weld quality. Contrarily, the vertical displacement of the sonotrode (displacement-controlled process) did not have to be updated to obtain consistent weld quality in the different spots. This higher robustness of the displacement-controlled process is believed to result from the fact that the vertical displacement of the sonotrode is directly linked to the physical phenomena occurring at the welding interface, e.g., melting and flow, but not so much to the boundary conditions or the surroundings of the welding overlap.

After the vibration phase of the welding process, the welded joint is allowed to cool down during the consolidation phase. In order to prevent deconsolidation of either the welded line or the adherends a sufficient force should be applied until the maximum temperature in the welding stack has decreased arguably below the glass transition temperature of the thermoplastic polymer. The main governing parameters of the consolidation phase are hence the consolidation force and the consolidation time. In the case of semi-crystalline thermoplastic polymers, the cooling rate during the consolidation phase will affect the degree of crystallinity in the weld line and, presumably, in the adjacent heat affected zone. The cooling rate depends on the thermal properties of the adherends, sonotrode and base as well as the welding force, vibration amplitude and the duration of the vibration phase. High force and amplitude values result in satisfactory weld quality after a very short vibration phase and hence limited heat transferred to the adherends (i.e., small heat affected zone in the throughthe-thickness direction) (Villegas, 2014). On the contrary, low force and amplitude values require a relative longer vibration phase and hence result in a wider heat affected zone to achieve satisfactory weld quality (Villegas, 2014). Consequently, cooling rates at the weld line can be expected to be significantly lower for a combination of low force and low amplitude during the vibration phase. This was indeed the result obtained by Koutras et al. (2018) when investigating the cooling rate and crystallinity at the weld line in ultrasonic welding of CF/PPS composites. Furthermore, the higher cooling rates obtained at high force $(1,000 \mathrm{~N})$ and high amplitude ( $86 \mu \mathrm{m}$, peak-to-peak) conditions were found to result in mainly amorphous weld lines. Interestingly it was found that, even though the much slower cooling in the low force $(300 \mathrm{~N})$ and low peak-to-amplitude ( $52 \mu \mathrm{m}$, peak-to-peak) conditions was not slow enough to render crystallization according to flash DSC results, the weld lines obtained in those conditions did feature a significant amount of crystallinity (see Figure 4). The

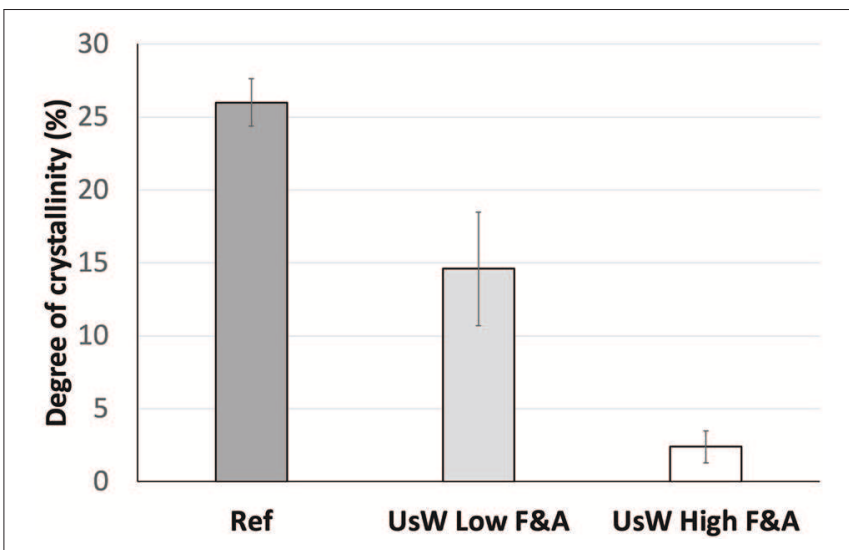

FIGURE 4 | Degree of crystallinity at the weld line in CF/PPS single-coupons welded in low force and low amplitude conditions ( $300 \mathrm{~N}, 52 \mu \mathrm{m})$ and in high force and high amplitude conditions $(1,000 \mathrm{~N}, 86 \mu \mathrm{m}$ peak-to-peak) as compared to reference values (press consolidated neat PPS) (Koutras et al., 2018).

potential cause of these apparent contradictory results might be strain-induced crystallization in the weld line.

\section{IN SITU MONITORING}

One of the main advantages of ultrasonic welding as compared to other welding processes for thermoplastic composites is that it offers relatively straightforward in situ process monitoring. In this context, in situ process monitoring should be understood as the real-time, non-intrusive monitoring of one or several variables that can be linked to the physical processes occurring during the welding process, e.g., melting and flow of the thermoplastic polymer at the welding interface, and ultimately to the weld quality. Process monitoring can be used as a tool to determine the processing windows as an efficient alternative to trial and error approaches (Villegas, 2014). It can also be used for inline quality assurance of the welded joints and ultimately to develop closed loop control welding processes in which the process parameters are automatically adjusted to ensure consistent weld quality (Tutunjian et al., 2018).

Already in the late 80's, Benatar and Gutowski showed in their work on ultrasonic welding of carbon fiber reinforced polyetherether-ketone (CF/PEEK) composites (Benatar and Gutowski, 1989) that the mechanical impedance of the welding interface is related to the flow of molten polymer. Using simplified models, they predicted a quick increase of the impedance of the interface upon meeting of all melt fronts (from several triangular energy directors at the welding interface). Likewise, they established theoretical relationships between the impedance of the interface and variables such as the dissipated power and the acceleration of the base/fixture. These two variables could be measured nonintrusively, i.e., without interfering with the welding process or the quality of the welded joint, by connecting a wattmeter to the converter and by mounting an accelerometer to the fixture, respectively. Their experimental research verified the theoretical 
predictions by showing a quick rise in the dissipated power and in the acceleration of the base/fixture when the melt fronts met and a good bond was produced.

The relationships of the power dissipated during the welding process (in order to keep a constant amplitude of vibration) and the vertical displacement of the sonotrode with the progression of the welding process and the weld quality were further investigated by Villegas and collaborators (Villegas, 2014, 2015; Villegas et al., 2015; Villegas and Palardy, 2017). It should be noted that this study was based on the use of modern micro-processor controlled ultrasonic welders, which offer the possibility to non-intrusively measure and record both the dissipated power and the displacement of the sonotrode during the welding process. According to this research the vibration phase of the welding process can be divided into several stages defined by changes in the dissipated power and the vertical displacement of the sonotrode. When a flat energy director is used, the process consists of five stages (Figure 5). In the first stage, the power increases until it reaches a peak, which relates to heating up of the energy director until the first occurrence of local melting. The second stage is characterized by a decrease in the power attributed to further gradual melting of the energy director. When the energy director is completely molten, it starts to flow out of the overlap under the effect of the welding force, which results in a sudden increase in power (stage 3). The power levels off in stage 4 when the matrix in the first layers of the composite adherends melt, enabling the creation of strong bonds. Finally, in stage 5 the power drops coinciding with excessive through-the-thickness heating, melting and squeeze flow in the adherends. Welded joints with the highest quality are therefore found in stage 4 of the welding process. In the particular case shown in Figure 5 corresponding to an ultrasonic welding process with a flat energy director, the displacement of the sonotrode does not add any new information to the stages defined by the power but it emphasizes the end of stage 3 and beginning of stage 4 characterized by a sudden increase of the displacement (squeeze out of the energy director). However, in the case of ultrasonic welding with traditional (triangular) energy directors the displacement of the sonotrode allows identifying two additional stages at the beginning of the process in which the triangular energy directors gradually heat up, melt and flow. These additional stages are characterized by a short plateau followed by a pseudo-linear displacement increase (Figure 6; Villegas and Palardy, 2017). It is interesting to note that this pseudo-linear displacement ends with the coalescence of the melt fronts from all the energy directors forming a continuous weld line, which subsequently undergoes the same five stages identified in ultrasonic welding with a flat energy director.

As a step further, Tutunjian et al. (2018) used the power dissipated by the ultrasonic welder, more specifically the time derivative of the power, to control ultrasonic welding of thermoplastic composites without an energy director. As mentioned earlier, the absence of energy director typically leads to overheating at the welding interface. However, in this research the authors concluded that by monitoring the time derivative of the power during the process and by lowering the amplitude of vibration when the control parameter exceeded a critical value,

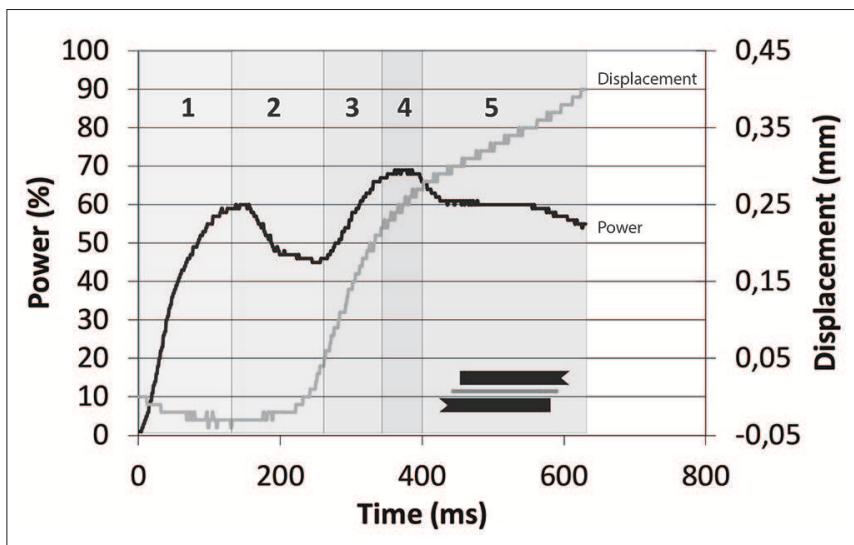

FIGURE 5 | Power and displacement curves for ultrasonic welding of CF/PPS single-lap coupons with flat energy director (energy director thickness $=$ $0.4 \mathrm{~mm}$, welding force $=500 \mathrm{~N}$, vibration amplitude $86 \mu \mathrm{m}$ peak-to-peak). Definition of stages $1-5$ in the welding process. Data obtained following the methodology described in Villegas et al. (2015).

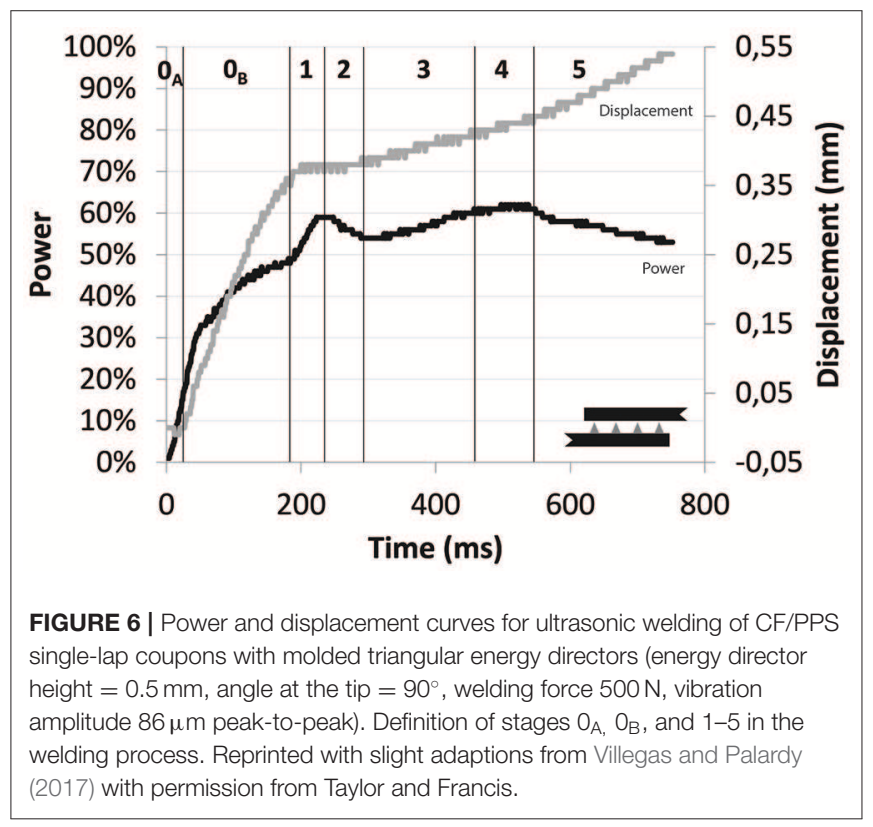

the temperature at the welding interface could be kept within an adequate range. This was made possible by the parallelism observed between the power dissipated during the welding process and the temperature measured at the welding interface.

\section{ULTRASONIC WELDING OF DISSIMILAR COMPOSITE MATERIALS}

Complex structures consist of different components and often these components are made out of different materials. Consequently welding of dissimilar materials is a topic of interest in the scientific and industrial communities. Within this topic, 
the use of ultrasonic welding for the welding of thermoplastic and thermoset composites has gained interest lately.

For the purpose of welding thermoset and thermoplastic composites the former needs to be made "weldable." This is typically achieved by "co-curing" a layer of neat thermoplastic layer, often referred to as "coupling layer," with one of the sides of the thermoset composite stack (Villegas and van Moorleghem, 2018). The connection between the thermoset composite and the thermoplastic coupling layer plays an important role in the strength and durability of the subsequent welded joints (Villegas and van Moorleghem, 2018). This connection can be achieved in different manners. For some material combinations, e.g., polyetherimide and epoxy, the thermoplastic resin in the coupling layer and the thermoset monomers are partially soluble and upon curing they generate a gradient interphase, typically from 10 to $400 \mu \mathrm{m}$ thick, between the thermoset composite and the thermoplastic coupling layer (Heitzmann et al., 2011; Villegas and van Moorleghem, 2018). This has, in the author's opinion, the potential to be the strongest and most durable type of connection. In other cases, when the melting temperature of the thermoplastic polymer is below the curing temperature of the thermoset resin, e.g., poly-vinyl-butyral (PVB) and highperformance epoxy, the thermoplastic polymer can partially flow into the thermoset composite resulting in mechanical interlocking between both materials (Lionetto et al., 2018). Finally, the thermoplastic coupling layer can be physically and/or chemically treated to promote adhesion with the thermoset resin during the curing process, e.g., poly-ether-ether-ketone treated with ultraviolet-ozone radiation and epoxy (Villegas and Vizcaino Rubio, 2015; Shi et al., 2017). However, the reliability and durability of this last type of connection maybe questionable (Villegas and van Moorleghem, 2018).

After the thermoset composite adherend is provided with a thermoplastic coupling layer, the latter needs to be welded to the thermoplastic composite adherend. Ultrasonic welding is very well suited for this type of welds owing to its very fast heat generation. One of the main challenges of welding such material combination is the fact that the welding temperature of the thermoplastic polymer is often well beyond the maximum usage temperature of the thermoset polymer. Consequently, thermal degradation of the thermoset composite adherend can be difficult to prevent during the welding process, as reported for relatively slow welding processes such as induction welding (Schieler and Beier, 2016; Lionetto et al., 2018). The very short heating time in ultrasonic welding (which can be as short as a couple of hundred milliseconds) makes it however possible to avoid thermal degradation of the thermoset polymer even when the welding temperature is higher than its degradation temperature (Villegas and Vizcaino Rubio, 2015), resulting in welded joints with excellent quality (Figure 7). To illustrate this point the results of a recent study by Tsiangou et al. (2019) show that $\mathrm{CF} / \mathrm{PEI}$ to CF/epoxy ultrasonically welded joints achieved the same (single-lap shear) strength as reference CF/PEI to CF/epoxy joints obtained through an autoclave co-curing process. In that study, a thin PEI film ( $60 \mu \mathrm{m}$-thick) was used on the CF/epoxy adherends as the thermoplastic coupling layer. As mentioned earlier, PEI and epoxy are partially soluble, which resulted in the

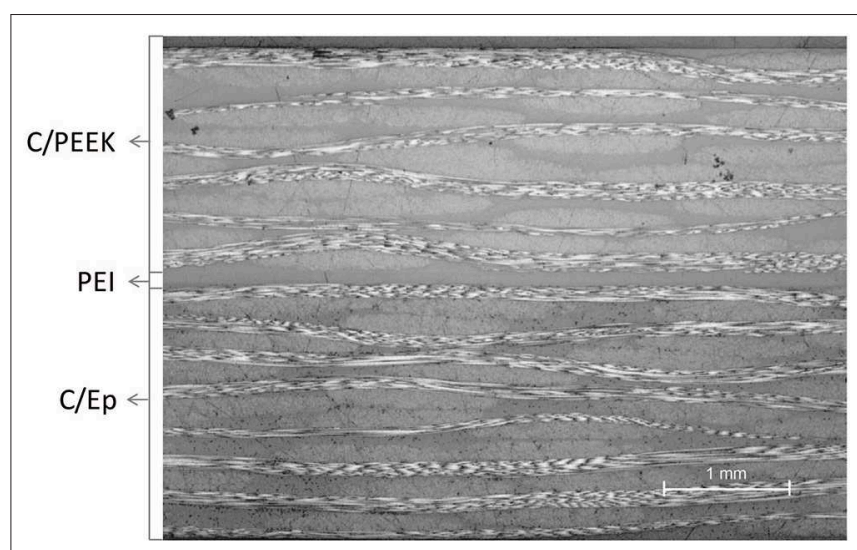

FIGURE 7 | Optical cross-section micrograph of a CF/PEEK to CF/epoxy ultrasonic welded single-lap coupon. The welded joint was achieved through a PEI coupling layer co-cured with the CF/epoxy adherend. Reprinted from Villegas and van Moorleghem (2018) with permission from Elsevier.

$\mathrm{CF} /$ epoxy and the PEI coupling layer being connected through a PEI-epoxy gradient interphase. The high strength of such connection was demonstrated by the fact that in the welded joints failure primarily occurred in the CF/PEI adherend and not in the interphase. Owing to the miscibility between PEI and PEEK polymers, PEI coupling layers have also been successfully used to weld CF/PEEK to CF/epoxy composites (Villegas and van Moorleghem, 2018). These two materials are typically found in modern passenger aircraft such as the Boeing 787 or the Airbus 350 aircraft and could, in the future, be potentially welded instead of mechanically fastened.

\section{UP-SCALING OF ULTRASONIC WELDING PROCESS}

Ultrasonic welding of thermoplastic composites is generally regarded as a static process in which only a relatively small area is welded at a time. For the welding of actual structures the ultrasonic welding process needs hence to be up-scaled, which can be done following two routes: sequential ultrasonic welding and continuous ultrasonic welding.

Sequential ultrasonic welding implies successively welding of spots in an overlap, resulting in a multi-spot, typically discontinuous, welded joint (Lu et al., 1991). Even though in discontinuous multi-spot welded joints the actual welded area is smaller than the overlap, this type of joints can be very structurally efficient. This is shown in a recent study by Zhao et al. (2019), which investigated the mechanical performance of multi-spot ultrasonic welded joints relative to mechanically fastened joints in CF/PPS composites. In this study, the welded spots were circular with $\sim 10 \mathrm{~mm}$ diameter and the mechanical fasteners were titanium Hi-Lok with $4 \mathrm{~mm}$ pin diameter. Joints in a single lap configuration and with different numbers of spots or fasteners (aligned and parallel to the load direction) were investigated. Despite the significantly lower pure-peel performance of single-spot welded joints observed in a previous 
study by the same authors (Zhao et al., 2016), the load carrying capability of single-lap spot multi-spot welded joints was similar (at most 10\% lower) than that of the mechanically fastened joints (Figure 8). Moreover, the welded joints displayed a number of similarities with the mechanically fastened joints, e.g., increasing load carrying capability when increasing the distance between adjacent spots or when increasing the number of spots as well as uneven load distribution in welds with more than two spots. These similarities can be expected to simplify the transition of one joining solution (mechanical fastening) to the other one (sequential ultrasonic welding) by using similar basic design rules. Contrarily to mechanically fastened joints, however, increasing the number of welded spots in a fixed overlap did not result in weakening of the adherends which can be expected to enable increased design flexibility. Likewise the damage caused to the composite adherends by the failure of the welded spots was much smaller and more localized than that caused by the failure of the mechanically fastened joints.

Continuous ultrasonic welding of thermoplastic composites can be achieved by for instance continuously translating the sonotrode along the line to be welded (Senders et al., 2016). A continuous welded seam is thus obtained as a result of such process at significantly high welding speeds (around 50 $\mathrm{mm} / \mathrm{s}$; Senders et al., 2016). Even though the continuous and static ultrasonic welding processes feature the same heating principles and mechanisms, the relative movement between the sonotrode and the parts to welded in continuous ultrasonic welding introduces a major difference in the welding process. In fact at each point in time during the static welding process the complete energy director is subjected to the same vibration history and hence can be assumed to be at the same stage of the welding process. However, in the continuous welding process the area of the energy director right under the sonotrode features varying times of exposure to the vibration and hence different stages of the welding process. According to this, at any point in time during the continuous ultrasonic welding process both fresh

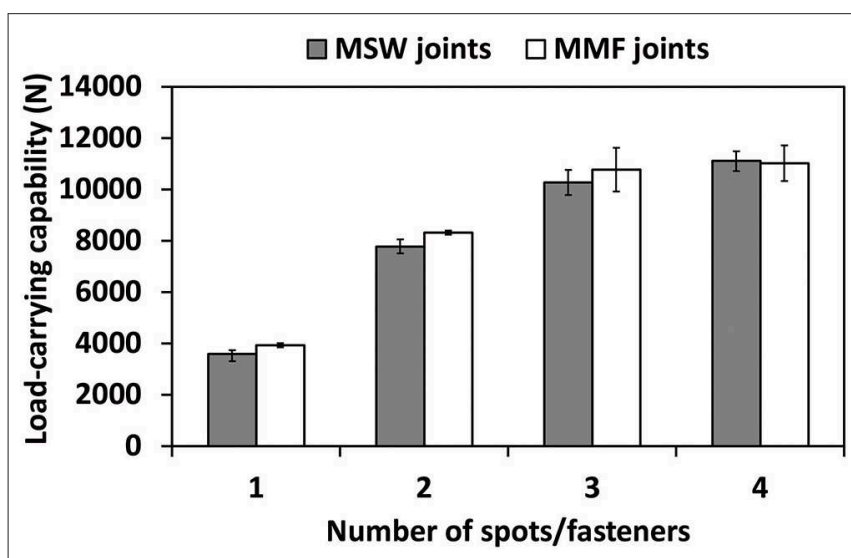

FIGURE 8 | Load carrying capability of CF/PPS multi-spot welded (MSW) single-lap joints as compared to multi mechanically fastened (MMF) single-lap joints. Reprinted with slight adaptations from Zhao et al. (2019) with permission from Elsevier. (unmolten) as well as molten energy director can be expected to coexist under the sonotrode, which highly constrains the downward displacement of the sonotrode during welding. As a consequence, continuous ultrasonic welding is more sensitive to the shape of the energy director than its static counterpart. In particular, flat energy directors have been found to result in continuous welds with non-uniform quality, whereas the use of more compliant energy directors, e.g., woven polymer meshes, has been found to significantly increase uniformity and weld quality (Jongbloed et al., 2018). Moreover, the presence of energy director at different stages of the welding process underneath the sonotrode is expected to make in situ monitoring of continuous ultrasonic welding a challenging task.

\section{CONCLUSIONS}

Some of the key aspects of ultrasonic welding of thermoplastic composites are the energy directors, process parameters, in situ monitoring of the welding process, welding of dissimilar composite materials and process upscaling.

Traditional energy directors such as the ones used in ultrasonic welding of unreinforced plastics are also successfully used to weld thermoplastic composites. However, differences in stiffness between fiber reinforced composites and the neat matrix make it possible to use simplified energy director solutions such as the flat energy directors. Ultrasonic welding of thermoplastic composites can also be successfully achieved without energy directors when the welding setup is provided with specific modifications and the process parameters are strictly controlled to prevent overheating.

The welding force and the vibration amplitude are the main process parameters controlling heating and cooling rates in ultrasonic welding of thermoplastic composites. They hence affect the heating time (and therefore the duration of the process for welded joints with optimal quality) as well as the degree of crystallinity in the weld line. Even though typical cooling rates in ultrasonic welding of thermoplastic composites are high, some combinations of process parameters (force and amplitude) can result in a substantial degree of crystallinity in the weld line, most likely promoted by the high strains developed during the process.

In situ monitoring is a relatively straightforward capability of the ultrasonic welding process. It can be satisfactorily used to define the processing parameters resulting in welds with the highest quality. Therefore, it can also be used as a tool to determine the quality of the welded joints and ultimately to control the process in a closed loop.

Owing to its very short heating times, ultrasonic welding allows welding of thermoplastic and thermoset composites while preventing thermal degradation of the latter even when exposed to welding temperatures higher than their degradation temperature. Thermoset composites can be made weldable through a co-cured thermoplastic layer on their joining surface.

Finally ultrasonic welding of actual thermoplastic composite structures can be achieved through either sequential welding 
of multi spots or continuous welding. Multi-spot welded joints behave similarly to mechanically-fastened joints but offer higher design flexibility owing to the fact the welded spots do not require drilling holes in the composite laminates. Continuous movement of the sonotrode relative to the parts allows obtaining continuous welded seams at relatively high speeds in continuous ultrasonic welding. The

\section{REFERENCES}

Ageorges, C., Ye, L., and Hou., M. (2001). Advances in fusion bonding techniques for joining thermoplastic matrix composites: a review. Compos. Part A Appl. Sci. Manufact. 32, 839-857. doi: 10.1016/S1359-835X(00)00166-4

Balle, F., Wagner, G., and Eifler, D. (2009). Ultrasonic metal welding of aluminium sheets to carbon fibre reinforced thermoplastic composites. Adv. Eng. Mater. 11, 35-39. doi: 10.1002/adem.200800271

Benatar, A., and Gutowski, T. G. (1989). Ultrasonic welding of PEEK graphite APC-2 composites. Polym. Eng. Sci. 29, 1705-1721. doi: $10.1002 /$ pen.760292313

Favaloro, M. (2018). Thermoplastic Composites in Aerospace-The Future Looks Bright. Composites World. Available online at: https://compositesworld.com/ columns/thermoplastic-composites-in-aerospace-past-present-and-future (accessed September 1, 2019).

Gao, Y. H., Zhi, Q., Lu, L., Liu, Z. X., and Wnag, P. C. (2018). Ultrasonic welding of carbon fiber reinforced nylon 66 composite without energy director. J. Manuf. Sci. Eng. 140:051009. doi: 10.1115/1.4039113

Gardiner, G. (2018). Thermoplastic Composite Demonstrators - EU Roadmap for Future Airframes. Composites World. Available online at: https://www. compositesworld.com/articles/thermoplastic-composite-demonstrators-euroadmap-for-future-airframes- (accessed September 1, 2019).

Grewel, D., Benatar, A., and Park, J. (2003). Plastics and Composites Welding Handbook. Munich: Hansen Gardner Publications.

Harras, B., Cole, K. C., and Vu-Khanh, T. (1996). Optimization of the ultrasonic welding of PEEK-carbon composites. J. Reinf. Plast. Comp. 15, 174-182. doi: $10.1177 / 073168449601500203$

Heitzmann, M. T., Hou, M., Veidt, M., Vandi, L. J., and Paton, R. (2011). Morphology of an interface between polyetherimide and epoxy prepreg. Adv. Mater. Res. 393-395, 184-188. doi: 10.4028/www.scientific.net/AMR.393-395.184

Ishikawa, T., Arnaoka, K., Masubuchi,Y., Yamamoto, T., Yamanaka, A., Arai, M., et al. (2018). Overview of automotive structural composite technology developments in Japan. Compos. Sci. Technol. 155, 221-241. doi: 10.1016/j.compscitech.2017.09.015

Jongbloed, B., Teuwen, J. J. E., Palardy, G., and Villegas, I. F., Benedictus, R. (2018). "Improving weld uniformity in continuous ultrasonic welding of thermoplastic composites," in Proceedings of the European Conference on Composite Materials - ECCM 18 (Athens).

Koutras, N., Villegas, I. F., and Benedictus, R. (2018). "Effect of ultrasonic welding process on the crystallinity at the welding interface of ultrasonically welded carbon fibre PPS joints," in Proceedings of the European Conference on Composite Materials - ECCM 18 (Athens).

Levy, A., Le Corre, S., and Villegas, I. F. (2014). Modelling the heating phenomena in ultrasonic welding of thermoplastic composites with flat energy directors. J. Mater. Process. Tech. 214, 1361-1371. doi: 10.1016/j.jmatprotec.2014.02.009

Li, Y., Arinez, J., Liu, Z., Lee, T. H., Fan, H. T., Xiao, G., et al. (2018). Ultrasonic welding of carbon fiber reinforced composite with variable blank holding force. J. Manuf. Sci. Eng. 140:091011. doi: 10.1115/1.4040427

Lionetto, F., Nicolas Morillas, M., Pappada, S., Buccoliero, G., Villegas, I. F., and Maffezzolli, A. (2018). Hybrid welding of carbon-fiber reinforced epoxy based composites. Compos. Part A Appl. Sci. 104, 32-40. doi: 10.1016/j.compositesa.2017.10.021

Liu, S. J., and Chang, I. T. (2001). Factors affecting the joint strength of ultrasonically welded polypropylene composites. Polym. Compos. 22, 132-141. doi: $10.1002 /$ pc. 10525 continuous ultrasonic welding process is however still at a low maturity level.

\section{AUTHOR CONTRIBUTIONS}

The author confirms being the sole contributor of this work and has approved it for publication.

Lu, H. M., Benatar, A., and He, F. G. (1991). "Sequential ultrasonic welding of PEEK/graphite composite plates," in Proceedings of ANTEC Conference (Montreal, QC), 2523-2526.

Nonhof, C. J., and Luiten, G. A. (1996). Estimates for process conditions during the ultrasonic welding of thermoplastics. Polym. Eng. Sci. 36, 1177-1183. doi: 10.1002/pen.10511

Palardy, G., Shi, H., Levy, A., Le Corre, S., and Villegas, I. F. (2018). A study on amplitude transmission in ultrasonic welding of thermoplastic composites. Compos. Part A Appl. Sci. 113, 339-349. doi: 10.1016/j.compositesa.2018.07.033

Palardy, G., and Villegas, I. F. (2017). On the effect of flat energy directors thickness on heat generation during ultrasonic welding of thermoplastic composites. Compos. Interface 24, 203-214. doi: 10.1080/09276440.2016.1199149

Potente, H. (1984). Ultrasonic welding - principles \& theory. Mater. Des. 5, 228-234. doi: 10.1016/0261-3069(84)90032-3

Ramarathnam, G., North, T. H., and Woodhams, R. T. (1992). Ultrasonic welding using tie-layer materials. Part II: factors affecting lap-shear strength of ultrasonic welds. Polym. Eng. Sci. 32, 612-619. doi: 10.1002/pen.760320907

Schieler, O., and Beier, U. (2016). Induction welding of hybrid thermoplasticthermoset composite parts. KMUTNB: International. J. Appl. Sci. Technol. 9, 27-36. doi: 10.14416/j.ijast.2015.10.005

Senders, F., van Beurden, M., Palardy, G., and Villegas, I. F. (2016). Zero flow: a novel approach to continuous ultrasonic welding of CF/PPS thermoplastic composite plates. Adv. Manuf. Polym. Compos. Sci. 2, 83-92. doi: $10.1080 / 20550340.2016 .1253968$

Shi, H., Sinke, J., and Benedictus, R. (2017). Surface modification of PEEK by UV irradiation for direct co-curing with carbon fibre reinforced epoxy prepregs. Int. J. Adhes. Adhes. 73, 51-57. doi: 10.1016/j.ijadhadh.2016.07.017

Tateishi, N., North, T. H., and Woodhams, R. T. (1992). Ultrasonic welding using tie-layer materials. Part I: analysis of process operation. Polym. Eng. Sci. 32, 600-611. doi: 10.1002/pen.760320906

Tolunay, M. N., Dawson, P. R., and Wang, K. K. (1983). Heating and bonding mechanisms in ultrasonic welding of thermoplastics. Polym. Eng. Sci. 23, 726-733. doi: 10.1002/pen.760231307

Tsiangou, E., Teixeira de Freitas, S., Villegas, I. F., and Benedictus, R. (2019). Investigation on energy director-less ultrasonic welding of polyetherimide (PEI)-based to epoxy-based composites. Compos. Part B Eng. 173:107014. doi: 10.1016/j.compositesb.2019.107014

Tutunjian, S., Dannemann, M., Fischer, F., Eroglu, O., and Modler, N. (2018). A control method for the ultrasonic spot welding of fiber-reinforced thermoplastic laminates through the weld-power time derivative. J. Manuf. Mater. Process. 3, 1-17. doi: 10.3390/jmmp3010001

Villegas, I. F. (2014). Strength development versus process data in ultrasonic welding of thermoplastic composites and its application to the definition of optimum process parameters. Compos. Part A Appl. Sci. 65, 27-37. doi: 10.1016/j.compositesa.2014.05.019

Villegas, I. F. (2015). In situ monitoring of ultrasonic welding of thermoplastic composites through power and displacement data. J. Thermoplast. Compos. 28, 66-85. doi: 10.1177/0892705712475015

Villegas, I. F., Moser, L., Yousefpour, A., Mitschang, P., and Bersee, H. E. N. (2012). Process and performance evaluation of ultrasonic, induction and resistance welding of advanced thermoplastic composites. J. Thermoplast. Compos. 26, 1007-1024. doi: 10.1177/0892705712456031

Villegas, I. F., and Palardy, G. (2017). Ultrasonic welding of CF/PPS composites with integrated triangular energy directors: melting, flow and weld strength development. Compos. Interface 24, 515-528. doi: 10.1080/09276440.2017.1236626 
Villegas, I. F., Valle Grande, B., Bersee, H. E. N., and Benedictus, R. (2015). A comparative evaluation between flat and traditional energy directors for ultrasonic welding of CF/PPS thermoplastic composites. Compos. Interface 22, 717-772. doi: 10.1080/09276440.2015.1053753

Villegas, I. F., and van Moorleghem, R. (2018). Ultrasonic welding of carbon/epoxy and carbon/PEEK composites through a PEI thermoplastic coupling layer. Compos. Part A Appl. Sci. 109, 75-83. doi: 10.1016/j.compositesa.2018. 02.022

Villegas, I. F., and Vizcaino Rubio, P. (2015). On avoiding thermal degradation during welding of high-performance thermoplastic composites to thermoset composites. Compos. Part A Appl. Sci. 77, 172-180. doi: 10.1016/j.compositesa.2015.07.002

Yan, J., Wang, X., Li, R., Xu, H., and Yang, S. (2007). The effects of energy director shape on temperature field during ultrasonic welding of thermoplastic composites. Key Eng. Mat. 353-358, 2007-2010. doi: 10.4028/www.scientific.net/KEM.353-358.2007

Zhang, Z., Wang, X., Luo, J., Zhang, Z., and Wang, L. (2010). Study on heating process of ultrasonic welding for thermoplastics. J. Thermoplast. Compos. 23, 647-664. doi: 10.1177/0892705709356493

Zhao, T., Broek, C., Palardy, G., Villegas, I. F., and Benedictus, R. (2018). Towards robust sequential ultrasonic spot welding of thermoplastic composites: welding process control strategy for consistent weld quality. Compos.
Part A Appl. Sci. Manufact. 109, 355-367. doi: 10.1016/j.compositesa.2018. 03.024

Zhao, T., Palardy, G., Villegas, I. F., Rans, C., Martinez, M., and Benedictus, R. (2016). Mechanical behaviour of thermoplastic composite spot-welded and mechanically fastened joints. Compos. Part B Eng. 112, 224-234. doi: 10.1016/j.compositesb.2016.12.028

Zhao, T., Rans, C., Villegas, I. F., and Benedictus, R. (2019). On sequential ultrasonic spot welding as an alternative to mechanical fastening in thermoplastic composite assemblies: a study on single-column multirow single-lap shear joints. Compos. Part A Appl. Sci. 120, 1-11. doi: 10.1016/j.compositesa.2019.02.013

Conflict of Interest: The author declares that the research was conducted in the absence of any commercial or financial relationships that could be construed as a potential conflict of interest.

Copyright $\odot 2019$ Villegas. This is an open-access article distributed under the terms of the Creative Commons Attribution License (CC BY). The use, distribution or reproduction in other forums is permitted, provided the original author(s) and the copyright owner(s) are credited and that the original publication in this journal is cited, in accordance with accepted academic practice. No use, distribution or reproduction is permitted which does not comply with these terms. 